\title{
New Amorphous Fluoropolymers of Tetrafluoroethylene with Fluorinated and Non-Fluorinated Tricyclononenes. Semiconductor Photoresists for Imaging at 157 and $193 \mathrm{~nm}$
}

\author{
Andrew E. Feiring,* Michael K. Crawford, William B. Farnham, Jerald Feldman, \\ Roger H. French, Christopher P. Junk, Kenneth W. Leffew, Viacheslav A. Petrov, \\ Weiming Qiu, Frank L. Schadt III, Hoang V. Tran, and Fredrick C. Zumsteg
}

DuPont Central Research \& Development, Experimental Station, P.O. Box 80328, Wilmington, Delaware 19880-0328

Received January 11, 2006; Revised Manuscript Received March 3, 2006

\begin{abstract}
Twenty-two tricyclo[4.2.1.0 2,5]non-7-ene (TCN) or 3-oxatricyclononene monomers, having fluorinated or nonfluorinated substituents on the four-membered rings, were prepared by cycloaddition reactions of functionalized olefins with norbornadiene or quadricyclane. Radical polymerizations with tetrafluoroethylene (TFE) and/or TFE and acrylates provided amorphous polymers with high solubility in standard organic solvents. The TFE/TCN dipolymers typically have glass transition temperatures of over $200{ }^{\circ} \mathrm{C}$, substantially higher than TFE copolymers with norbornene. Perfluoroalkyl sulfonyl fluoride groups can be incorporated in the side chains of the TCN monomers giving soluble copolymers. Polymers which also incorporated acrylate monomers were prepared using a semibatch process to control composition. Selected polymers incorporating tertiary alkyl ester groups from the TCN monomer or acrylates have shown good image formation when compounded with a photoacid generator, imaged with 157 or $193 \mathrm{~nm}$ light, and developed using aqueous base.
\end{abstract}

\section{Introduction}

Fluorinated polymers continue to be of intense commercial and scientific interest because of their unique combination of properties, including high thermal and chemical stability and low surface energy, dielectric constant, refractive index, and flammability. ${ }^{1}$ On the other hand, the traditional highly fluorinated polymers, such as poly(tetrafluoroethylene), are difficult to process, are practically insoluble, and have high crystallinity, which limits optical applications. Adding enough acyclic comonomer to eliminate crystallinity tends to give polymers with low glass transition temperatures. ${ }^{2}$ Amorphous, high $T_{\mathrm{g}}$ perfluoropolymers (TeflonAF and Cytop) have been developed using cyclic or cyclizable monomers but they are soluble only in expensive, highly fluorinated solvents. . $^{3,4}$

Several years ago, we began investigating amorphous copolymers of tetrafluoroethylene (TFE) and polycyclic olefins, such as norbornene, as the binder polymer for photoresists for semiconductor manufacture at $157 \mathrm{~nm} .{ }^{5}$ This was based on our discovery that the TFE/norbornene copolymer has high transparency at this very high energy irradiation wavelength and is resistant to the ion etching used in the manufacturing process, both critical features for this application which was then expected to be commercial in the middle of this decade. Our fully functional $157 \mathrm{~nm}$ photoresist (Figure 1) incorporated tertbutyl acrylate as the acid-labile solubility switch for imaging and the pendant fluoro alcohol groups as highly transparent aids for dissolution in aqueous base. ${ }^{6-8}$ Other groups have also reported the utility of hexafluoro-2-propanol groups in $157 \mathrm{~nm}$ photoresists as highly transparent components with phenol-like acidity to aid dissolution in aqueous base. ${ }^{9,10}$ We have recently described copolymers of TFE and a norbornene substituted by two hexafluoro-2-propanol substituents which show exceptional transparency. ${ }^{11}$

Photolithography at $157 \mathrm{~nm}$ has now largely disappeared from the semiconductor road map due to the development of 193 immersion lithography as a less expensive alternative for

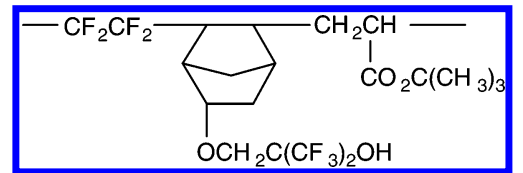

Figure 1. TFE/NB-F-OH/tert-butyl acrylate terpolymer for $157 \mathrm{~nm}$ imaging.

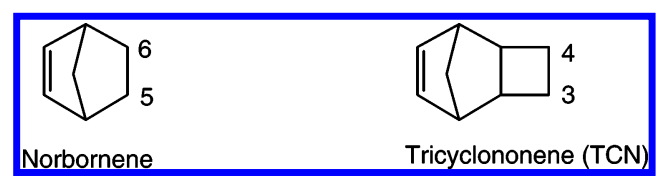

Figure 2. Polycyclic olefin structures.

generating features at the $65 \mathrm{~nm}$ and smaller nodes. We, therefore, retooled our effort toward development of fluorinated photoresists for 193 imaging. Although fluorine is not required for transparency at $193 \mathrm{~nm}$, our results suggested that the TFE/ polycyclic olefin/acrylate polymers may have performance advantages. Typical photoresist binders for $193 \mathrm{~nm}$ imaging are based on norbornene/maleic anhydride/tert-alkyl acrylate ${ }^{12}$ or poly(meth)acrylates with polycyclic and acid-labile groups in side chains. ${ }^{13-23}$ The TFE/polycyclic olefin/acrylate copolymers eliminate the hydrolytically sensitive maleic anhydride moiety of the former class while adding an etch-resistant polycyclic group to the backbone relative to the latter class. We have also described improved line edge roughness in the fluoropolymers relative to the incumbent acrylate or methacrylate polymers. ${ }^{24}$

During this work, we wished to explore polymers with greater functionality within the polycyclic olefin component. It quickly became apparent, however, that adding additional substituents to the 5 and 6 positions of the norbornene ring tended to inhibit copolymerizations with tetrafluoroethylene, presumably due to steric effects. We turned our attention to the tricyclo[4.2.1.0 2,5$]$ non-7-ene (TCN) system because substituents at the 3 and 4 positions (Figure 2) are more remote from the double bond and because a variety of substituted TCN derivatives with exoorientation of the four-membered ring could be prepared. Several 


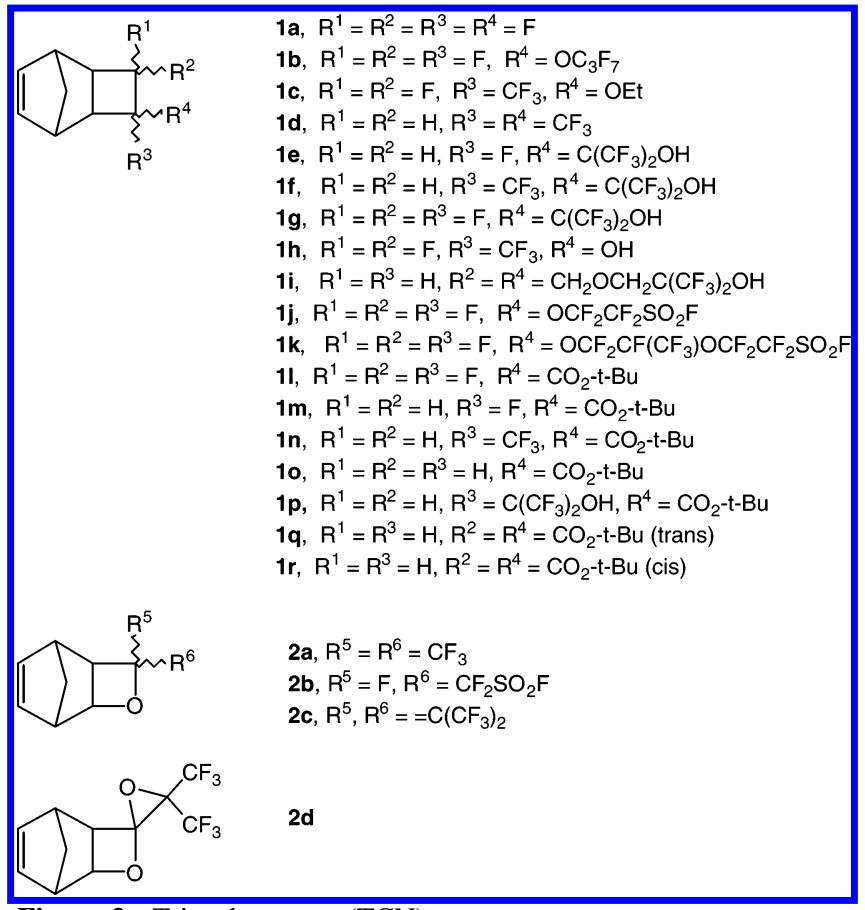

Figure 3. Tricyclononene (TCN) monomers.

partially fluorinated and/or ester-containing TCN monomers and their metal-catalyzed addition polymers for $157 \mathrm{~nm}$ imaging have been described. ${ }^{25}$

We now report the synthesis of 22 TCN or oxa-TCN monomers (Figure 3), most of which are new compounds. Novel copolymers of the TCNs with TFE, with TFE and NB-F-OH and with TFE and acrylates have been prepared and characterized. While not expecting the extreme properties of perfluoropolymers, some of the dipolymers with fluorinated TCN derivatives show interesting thermal, optical and electronic properties while retaining solubility in standard organic solvents. Polymers of TFE and TCN monomers with appropriate functionality on the TCN or with an added acrylate component were prepared, and some have shown good performance in chemically amplified imaging processes.

\section{Results and Discussion}

Monomer Syntheses. Because of the tendency of some highly fluorinated olefins to undergo $2+2$ cycloaddition reactions, ${ }^{26} \mathbf{1 a}, \mathbf{1 b}, \mathbf{1 c}, \mathbf{1 j}$, and $\mathbf{1 k}$ are readily obtained in one step by reaction of norbornadiene with the corresponding fluorinated olefins (Scheme 1).

The remaining monomers require use of quadricyclane (tetracyclo[3.2.0.0 $\left.0^{2,7} \cdot 0^{4,6}\right]$ heptane) as the cycloaddition partner to avoid formation of the undesired deltacyclane (tetracyclo$\left[2.2 .1 .2^{3,5} \cdot 0^{2,6}\right]$ nonane) derivatives by the usual $2+2+2$ cycloaddition of norbornadienes to olefins (Scheme 2). ${ }^{27}$ Thus, reactions of quadricyclane with hexafluoroisobutylene, tert-butyl acrylate, di-tert-butyl fumarate, di-tert-butyl maleate, hexafluoroacetone, $\mathrm{FC}(\mathrm{O}) \mathrm{CF}_{2} \mathrm{SO}_{2} \mathrm{~F}$, and bis(trifluoromethyl)ketene ${ }^{28}$ provided monomers $\mathbf{1 d}, \mathbf{1 0}, \mathbf{1 q}, \mathbf{1 r}, \mathbf{2 a}, \mathbf{2 b}$, and $\mathbf{2 c}$, respectively. Monomers $\mathbf{1 l}, \mathbf{1 m}$, and $\mathbf{1 n}$ were prepared by reaction of the corresponding fluorinated acrylic acid fluorides with quadricyclane followed by conversion of the acid fluoride to the tertbutyl ester using potassium tert-butoxide.

Monomers 1e-1g having hexafluoro 2-propanol groups pendant to the four-membered ring were prepared by addition of the appropriate acrylic acid halide to quadricyclane. The carbonyl groups were reacted with trifluoromethyltrimethylsi-
Scheme 1. Monomer Synthesis

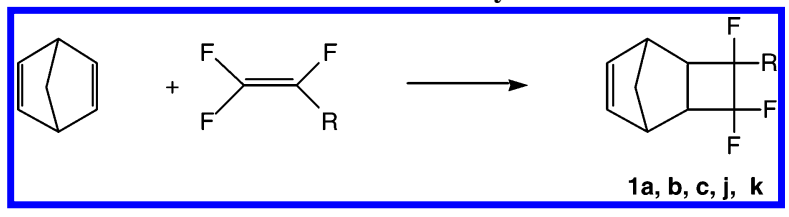

Scheme 2. Cycloaddition Reactions of Quadricyclane and Norbornadiene

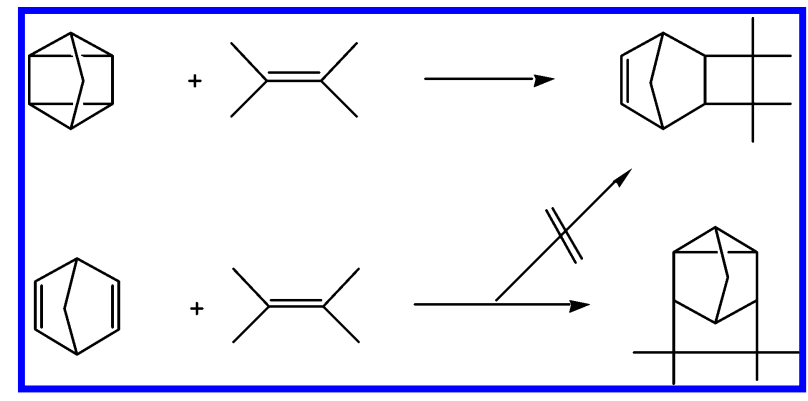

Scheme 3. Synthesis of Fluoro Alcohol Containing Monomers

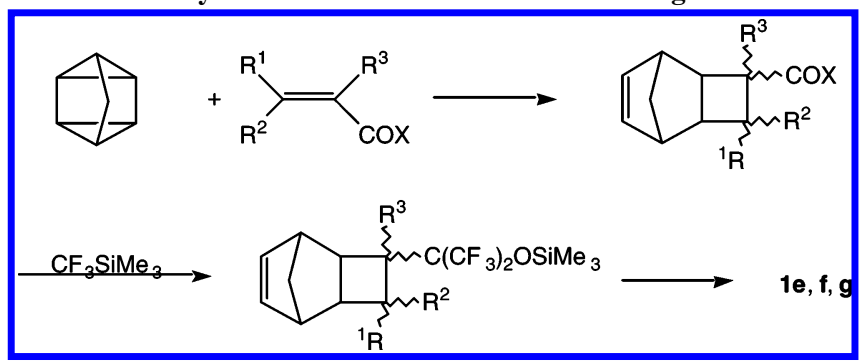

Scheme 4. Synthesis of $1 \mathrm{~h}$

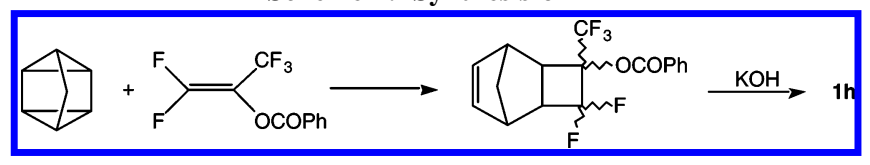

Scheme 5. Synthesis of 1p

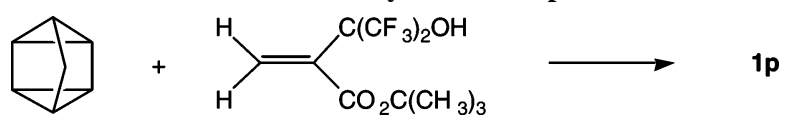

lane $\mathrm{e}^{29,30}$ to afford the desired bis(trifluoromethyl) alcohols as their trimethylsilyl ethers. The later are readily hydrolyzed to afford 1e-1g (Scheme 3).

Monomer $\mathbf{1 h}$ was prepared by cycloaddition of the known 1,1,3,3,3-pentafluoro-2-propenyl benzoate ${ }^{31}$ with quadricyclane, followed by hydrolysis of the benzoate group (Scheme 4). Cycloaddition of the known ${ }^{32,33}$ Baylis-Hillman adduct of hexafluoroacetone and tert-butyl acrylate afforded the monomer 1p which contains both fluoro alcohol and ester substituents (Scheme 5).

The novel spirocyclic monomer $\mathbf{2 d}$ was obtained from $\mathbf{2 c}$ by epoxidation using alkaline sodium hypochlorite.

Synthesis and Properties of TFE Dipolymers. ${ }^{34,35}$ Copolymers of TFE and selected TCN monomers (Table 1) were prepared by polymerizations in $200 \mathrm{~mL}$ Hastelloy pressure vessels using Perkadox 16 (di-tert-butylcyclohexylperoxydicarbonate) as initiator and Solkane $365 \mathrm{mfc}(1,1,1,3,3$-pentafluorobutane) as solvent at $50{ }^{\circ} \mathrm{C}$. The pentafluorobutane solvent was found to dissolve the monomers and polymers and should have very low propensity for chain transfer. Typically a 1.51.9-fold excess of TFE to the TCN monomer was charged to the reactor due to the partition of this gaseous monomer between the liquid and vapor state. Polymers were isolated by precipitation into excess hexane, followed by drying in a vacuum oven. 
Table 1. TFE/TCN Dipolymers

\begin{tabular}{|c|c|c|c|c|c|c|c|}
\hline polymer & $\begin{array}{c}\text { monomer } \\
(\operatorname{amt}(\mathrm{mol}))\end{array}$ & $\begin{array}{l}\text { mol \% } \\
\text { initiator }^{a}\end{array}$ & $\begin{array}{c}\operatorname{convn}^{b} \\
(\%)\end{array}$ & $M_{\mathrm{n}} / M_{\mathrm{w}} / \mathrm{PD}$ & $\begin{array}{c}T_{\mathrm{g}} \\
\left({ }^{\circ} \mathrm{C}\right)\end{array}$ & $\begin{array}{l}T_{\mathrm{d}}{ }^{c} \\
\left({ }^{\circ} \mathrm{C}\right)\end{array}$ & $\begin{array}{c}\mathrm{abs}^{d} \\
\left(\mu \mathrm{m}^{-1}\right)\end{array}$ \\
\hline 3 & $1 \mathbf{a}(0.245)$ & 0.57 & 24 & $14900 / 25200 / 1.69$ & 236 & 479 & \\
\hline 3 & $1 \mathrm{a}(0.245)$ & 2.28 & 69 & $8700 / 20600 / 2.36$ & 220 & 465 & 0.69 \\
\hline 4 & 1b $(0.175)$ & 2.28 & 68 & $3700 / 12400 / 3.37$ & 175 & 445 & \\
\hline 5 & 1c $(0.12)$ & 2.09 & 20 & $5300 / 8700 / 1.63$ & 191 & 377 & 1.09 \\
\hline 6 & $1 d(0.20)$ & 2.01 & 23 & $5700 / 7800 / 1.37$ & 203 & 437 & 0.61 \\
\hline 7 & le $(0.12)$ & 2.01 & 16 & $4200 / 7000 / 1.67$ & 207 & 312 & 1.44 \\
\hline 8 & $\mathbf{1 f}(0.12)$ & 2.26 & 18 & $4200 / 6200 / 1.49$ & 209 & 359 & 1.23 \\
\hline 9 & $1 \mathrm{~g}(0.11)$ & 2.28 & 37 & $4800 / 7400 / 1.54$ & 228 & 320 & 0.82 \\
\hline 10 & 1h $(0.12)$ & 2.13 & 25 & $5300 / 9300 / 1.75$ & 222 & 410 & 0.76 \\
\hline 11 & $\mathbf{1 i}(0.18)$ & 2.50 & 61 & $14400 / 26600 / 1.85$ & 96 & 360 & \\
\hline 12 & $\mathbf{1 j}(0.40)$ & 1.00 & 53 & $17900 / 26900 / 1.50$ & 187 & 438 & \\
\hline 13 & $\mathbf{1 k}(0.30)$ & 1.00 & 30 & $8300 / 10200 / 1.23$ & 112 & 441 & \\
\hline 14 & $\mathbf{2 a}(0.245)$ & 2.25 & 60 & $10800 / 17500 / 1.62$ & 212 & 437 & 0.55 \\
\hline 15 & $\mathbf{2 b}(0.20)$ & 2.00 & 55 & $5600 / 13500 / 2.42$ & & 333 & \\
\hline 16 & $2 c(0.20)$ & 2.00 & 61 & $12400 / 22400 / 1.81$ & 236 & 376 & 1.65 \\
\hline 17 & 2d $(0.105)$ & 2.30 & 63 & $10400 / 17700 / 1.70$ & 222 & 343 & \\
\hline
\end{tabular}

${ }^{a}$ On the basis of moles of TCN monomer alone. ${ }^{b}$ Conversion of the TCN monomer, calculated assuming a $1 / 1 \mathrm{TFE} / \mathrm{TCN}$ composition. ${ }^{c} 10 \%$ weight loss temperature by TGA under $\mathrm{N}_{2} .{ }^{d}$ Absorbance of thin films at $157 \mathrm{~nm}$.

Table 2. TFE/NB-F-OH/TCN-ester Polymers

\begin{tabular}{|c|c|c|c|c|c|c|c|c|}
\hline polymer & monomers $^{a}(\operatorname{amt}(\mathrm{mol}))$ & $\begin{array}{c}\text { mol \% } \\
\text { initiator }^{b}\end{array}$ & $\begin{array}{c}\text { convn }^{c} \\
(\%)\end{array}$ & $M_{\mathrm{n}} / M_{\mathrm{w}} / \mathrm{PD}$ & $\begin{array}{c}T_{\mathrm{g}} \\
\left({ }^{\circ} \mathrm{C}\right)\end{array}$ & $\begin{array}{c}T_{\mathrm{d}} \\
\left({ }^{\circ} \mathrm{C}\right)\end{array}$ & $\begin{array}{c}\text { abs at } \\
157 \mathrm{~nm}\end{array}$ & composition $^{d}$ \\
\hline 18 & 11/NB-F-OH $(0.120 / 0.125)$ & 2.61 & $42 / 52$ & $3500 / 7200 / 2.03$ & 195 & 203 & 1.63 & $45 / 24 / 31$ \\
\hline 19 & $\mathbf{1 m} / \mathrm{NB}-\mathrm{F}-\mathrm{OH}(0.091 / 0.14)$ & 2.42 & $31 / 28$ & $4700 / 10000 / 2.15$ & 171 & 268 & 1.84 & $45 / 23 / 32$ \\
\hline 20-1 & 1n/NB-F-OH $(0.035 / 0.21)$ & 2.23 & $29 / 31$ & $5900 / 10500 / 1.77$ & 162 & 358 & 1.13 & $47 / 7 / 46$ \\
\hline 20-2 & $1 \mathbf{n} / \mathrm{NB}-\mathrm{F}-\mathrm{OH}(0.07 / 0.175)$ & 2.28 & $31 / 32$ & $6600 / 10800 / 1.64$ & 166 & 332 & 1.37 & $46 / 15 / 39$ \\
\hline 21 & 1o/NB-F-OH $(0.12 / 0.16)$ & 2.28 & $26 / 17$ & $4900 / 6700 / 1.35$ & 162 & 299 & 2.4 (est) & $45 / 29 / 25$ \\
\hline 22 & 1p/NB-F-OH $(0.035 / 0.21)$ & 2.28 & $30 / 26$ & $5300 / 9200 / 1.74$ & 166 & 325 & 1.9 & $45 / 9 / 46$ \\
\hline 23-1 & $\mathbf{1 q} / \mathrm{NB}-\mathrm{F}-\mathrm{OH}(0.056 / 0.189)$ & 2.28 & $33 / 25$ & $5000 / 8900 / 1.78$ & 169 & 295 & 1.98 & $46 / 15 / 39$ \\
\hline 23-2 & $1 \mathrm{q} / \mathrm{NB}-\mathrm{F}-\mathrm{OH}(0.07 / 0.43)$ & $3.36^{e}$ & $51 / 34$ & $7100 / 11600 / 1.63$ & 157 & 352 & 1.47 & $49 / 10 / 41$ \\
\hline 23-3 & $1 \mathrm{q} / \mathrm{NB}-\mathrm{F}-\mathrm{OH}(0.06 / 0.44)$ & $3.36^{e}$ & $46 / 26$ & $7600 / 11100 / 1.46$ & 163 & 356 & 1.5 (est) & $48 / 10 / 42$ \\
\hline
\end{tabular}

${ }^{a}$ In addition to TFE. ${ }^{b}$ On the basis of moles of the TCN and NB-F-OH monomers, not including TFE which is present in excess. ${ }^{c}$ Conversion of monomer $1 / \mathrm{NB}-\mathrm{F}-\mathrm{OH}$ calculated from weight of isolated polymer and measured polymer composition. ${ }^{d}$ Mole $\%$ as determined by carbon and fluorine NMR. Listed in order TFE/1/NB-F-OH. ${ }^{e}$ Prepared using HFPO-dp initiator.

Conversions of the 3-substituted-3,4,4-trifluorotricyclononenes $\mathbf{1 a}, \mathbf{1 b}$, and $\mathbf{1} \mathbf{j}$, plus $\mathbf{1 i}$ and the oxatricyclononenes $\mathbf{2}$, were generally greater than $50 \%$ in these copolymerizations in the presence of $2-2.5 \mathrm{~mol} \%$ of initiator. Other derivatives, especially the fluoro alcohol substituted compounds $\mathbf{1 e}-\mathbf{1 h}$, gave generally lower conversions and molecular weights. It is not known if these differences are intrinsic to these monomers or reflect relative purities.

The dipolymers are generally soluble in moderately polar organic solvent such as THF, methylene chloride and chloroform and insoluble in hydrocarbons and methanol. One exception is the highly fluorinated polymer 4 which requires a fluorocarbon solvent, such as hexafluorobenzene, for ready dissolution at room temperature. They were characterized by GPC, DSC, and TGA (Table 1) and by proton and fluorine NMR and elemental analysis (Supporting Information). The fluorine NMR spectra show a characteristic envelope of peaks in the region -95 to $-125 \mathrm{ppm}$ which is assigned to the backbone $\mathrm{CF}_{2}$ groups from TFE. Some peaks from the TCN monomers were generally sufficiently resolved from the TFE peaks to allow compositions to be calculated from the integrals. Generally they were found to be within a few percent of the expected 50/50 ratio.

The dipolymers generally have glass transition temperatures in the range of 175 to $240{ }^{\circ} \mathrm{C}$, substantially greater than the TFE/norbornene dipolymer $\left(150{ }^{\circ} \mathrm{C}\right)$. Notable exceptions are polymers $\mathbf{1 1}$ and $\mathbf{1 3}$ which possess long flexible side chains. Thermal stability was assayed by TGA and is reported in Table 1 as the temperature at which $10 \%$ weight loss occurs under nitrogen. The polymers from TCN monomers with simple fluorinated side chains generally have decomposition temperatures in excess of $400{ }^{\circ} \mathrm{C}$. Addition of more complex side chains tends to lower the decomposition temperature into the $300-400{ }^{\circ} \mathrm{C}$ range.

Vacuum ultraviolet (VUV) transmission measurements of many of these fluoropolymers were made as described in the Experimental Section. The TFE/TCN dipolymers generally showed high transparency at $157 \mathrm{~nm}$ as shown in the final column in Table 1 . Polymers 3, 6, 10, and $\mathbf{1 4}$ were found to be significantly more transparent than the TFE/norbornene dipolymer (ca. 1.30) which was prepared under similar conditions indicating that a fluorinated four-membered ring does not intrinsically increase absorption.

The optical and electronic properties of the TFE/TCN copolymers are under investigation and will be described elsewhere. It can be noted, however, that the dielectric constant of polymer 3 was found to be 2.1 so it is relatively fluoropolymer-like despite its solubility in common organic solvents. It is also noted that polymers $\mathbf{1 2}$ and $\mathbf{1 3}$ possess fluoroalkylsulfonyl groups as side chains and therefore can function as soluble precursors to polymers having very weakly basic perfluoroalkylsulfonate pendant groups. Such materials are of continuing interest for a variety of applications such as lithium ion battery membranes. Hydrolysis of the sulfonyl fluoride groups has been demonstrated; properties of the resulting polymers will be reported elsewhere.

Polymers of TFE, NB-F-OH, and TCN-Esters. Polymers comprising TFE, $\mathrm{NB}-\mathrm{F}-\mathrm{OH}$ and the tert-butyl estersubstituted TCN monomers $\mathbf{1 l}-\mathbf{1 q}$ were prepared mainly as photoresist candidates for imaging at $157 \mathrm{~nm}$. Thus, the TCN esters are used in place of the tert-butyl acrylate component in our original $157 \mathrm{~nm}$ photoresist to provide the acid labile solubility switch for imaging. Selected polymers 18-23 are summarized in Table 2. 
Table 3. TFE/TCN/Acrylate Polymers

\begin{tabular}{|c|c|c|c|c|c|c|c|c|c|}
\hline polymer & $\begin{array}{l}\text { monomers }^{a} \text { (molar feed ratio) } \\
\quad \text { (total moles) }\end{array}$ & $\begin{array}{l}\text { TFE } \\
\text { (psi) }\end{array}$ & $\begin{array}{l}\text { mole } \% \\
\text { initiator }^{b}\end{array}$ & $\begin{array}{l}\text { yield }^{c} \\
(\mathrm{~g})\end{array}$ & conversion $^{d}$ & $M_{\mathrm{w}} / \mathrm{PD}$ & $\begin{array}{c}T_{\mathrm{g}} \\
\left({ }^{\circ} \mathrm{C}\right)\end{array}$ & $\begin{array}{c}T_{\mathrm{d}} \\
\left({ }^{\circ} \mathrm{C}\right)\end{array}$ & composition $^{e}$ \\
\hline 24-1 & 1a/t-BuAc (86/14) (0.5) & 320 & 1.36 & 27.8 & $17 / 76$ & $11000 / 1.40$ & 173 & 238 & $35 / 37 / 28$ \\
\hline 24-2 & 1a/t-BuAc $(77 / 23)(0.55)$ & 300 & 1.36 & 35.2 & $20 / 74$ & $11800 / 1.35$ & & 234 & $29 / 34 / 37$ \\
\hline 24-3 & 1a/t-BuAc $(70 / 30)(0.6)$ & 270 & 1.83 & 39.1 & $21 / 67$ & $13300 / 1.43$ & 155 & 232 & $24 / 33 / 44$ \\
\hline 24-4 & $\mathbf{1 a} / \mathrm{t}-\mathrm{BuAc}(58 / 42)(0.6)$ & 240 & 2.41 & 44.4 & $27 / 63$ & $17000 / 1.65$ & 141 & 229 & $20 / 30 / 51$ \\
\hline 25 & 1a/NB $-\mathrm{F}-\mathrm{OH} / \mathrm{PinAc} / \mathrm{HAdA}(14 / 58 / 14 / 14)(0.6)$ & 280 & 0.7 & 54.7 & $12 / 25 / 75 / 69$ & $30900 / 2.38$ & 174 & 227 & $14 / 4 / 35 / 25 / 23$ \\
\hline 26 & 1h/t-BuAc $(85 / 15)(0.5)$ & 320 & 2.20 & 48.3 & $32 / 78$ & $8500 / 1.77$ & 190 & 279 & $31 / 48 / 21$ \\
\hline 27 & 1h/PinAc/MAdA/HAdA (58/14/7/21) (0.6) & 240 & 2.40 & 89.5 & $38 / 94 / 114 / 104$ & $10100 / 2.28$ & & 225 & $1130 / 18 / 11 / 30$ \\
\hline 28 & 1h/PinAc/HAdA (72/14/14) (0.6) & 280 & 0.67 & 61.3 & 28/91/84 & $16000 / 2.05$ & & 227 & $13 / 39 / 25 / 23$ \\
\hline 29 & 1p/NB-F-OH/PinAc/HAdA $(18 / 54 / 14 / 14)(0.5)$ & 280 & 0.67 & 44.3 & $24 / 20 / 64 / 68$ & $25000 / 2.38$ & & 222 & $17 / 11 / 28 / 23 / 21$ \\
\hline 30-1 & 1q/NB-F-OH/HAdA $(11 / 79 / 10)(0.5)$ & 340 & 2.20 & 54.3 & $44 / 25 / 90$ & $10700 / 1.55$ & 174 & 264 & $33 / 10 / 39 / 18$ \\
\hline 30-2 & 1q/NB-F-OH/HAdA $(11 / 79 / 10)(0.5)$ & 340 & 0.86 & 37.6 & $30 / 16 / 80$ & $15500 / 1.64$ & 184 & 278 & $29 / 10 / 38 / 24$ \\
\hline 31 & 1q/NB-F-OH/GBLA $(11 / 79 / 10)(0.5)$ & 340 & 2.20 & 59.2 & $40 / 31 / 80$ & $9600 / 1.61$ & 190 & 300 & $36 / 8 / 43 / 14$ \\
\hline 32 & 1q/NB-F-OH/NBLA $(11 / 79 / 10)(0.5)$ & 340 & 2.20 & 47.1 & $32 / 24 / 71$ & $9900 / 1.73$ & 164 & 295 & $34 / 8 / 42 / 16$ \\
\hline 33 & 1q/NB-F-OH/PinAc/HAdA $(15 / 44 / 14 / 28)(0.5)$ & 240 & $2.40^{f}$ & 89.0 & $49 / 49 / 102 / 91$ & $9700 / 2.03$ & & 228 & $15 / 9 / 27 / 18 / 32$ \\
\hline 34 & 1q/NB-F-OH/t-BuAc/HAdA $(15 / 44 / 14 / 28)(0.5)$ & 240 & $2.40^{f}$ & 81.1 & $64 / 44 / 31 / 97$ & $10000 / 1.98$ & 157 & 246 & $16 / 13 / 27 / 6 / 38$ \\
\hline 35 & 1q/NB-F-OH/MAdA/HAdA $(15 / 44 / 14 / 28)(0.5)$ & 240 & $2.40^{f}$ & 74.6 & $72 / 37 / 70 / 68$ & $10400 / 1.75$ & 168 & 245 & $10 / 17 / 26 / 16 / 31$ \\
\hline 36 & 1q/NB-F-OH/PinAc/GBLA $(15 / 44 / 14 / 28)(0.6)$ & 240 & $2.40^{f}$ & 97.8 & $54 / 52 / 89 / 98$ & $9400 / 2.06$ & 163 & 223 & $10 / 10 / 29 / 16 / 35$ \\
\hline 37 & 1q/NB-F-OH/MAdA/GBLA (15/44/14/28) (0.6) & 240 & $2.40^{f}$ & 94.8 & $54 / 46 / 92 / 90$ & $10100 / 1.78$ & 148 & 223 & $9 / 11 / 28 / 18 / 35$ \\
\hline 38 & $1 \mathrm{q} / \mathrm{NB}-\mathrm{F}-\mathrm{OH} / \mathrm{NB}-\mathrm{di}-\mathrm{F}-\mathrm{OH} / \mathrm{HAdA}(13 / 64 / 13 / 10)(0.5)$ & 340 & 0.80 & 31.5 & $13 / 13 / 14 / 69$ & $13800 / 1.82$ & 181 & 250 & $27 / 9 / 31 / 7 / 26$ \\
\hline 39-1 & $\mathbf{1} \mathbf{r} / \mathrm{NB}-\mathrm{F}-\mathrm{OH} / \mathrm{HAdA}(11 / 79 / 10)(0.5)$ & 340 & 2.20 & 50.0 & $33 / 23 / 87$ & $9100 / 1.49$ & 168 & 270 & $34 / 8 / 40 / 19$ \\
\hline 39-2 & 1r/NB-F-OH/HAdA $(11 / 79 / 10)(0.5)$ & 340 & 0.86 & 28.0 & $17 / 11 / 86$ & $16600 / 1.63$ & 181 & 267 & $24 / 8 / 36 / 32$ \\
\hline
\end{tabular}

${ }^{a}$ Excluding TFE. ${ }^{b}$ Of total monomers excluding TFE. ${ }^{c}$ Isolated yield of solid polymer after two precipitations. ${ }^{d}$ Of monomers listed in second column. Calculated from polymer composition and isolated yield. ${ }^{e}$ Mole percent as determined by NMR. TFE listed first, followed by monomers as listed in column 2. ${ }^{f}$ Polymerizations run in methyl acetate in the presence of $40 \mathrm{~mol} \% \mathrm{THF}$ as chain transfer agent.

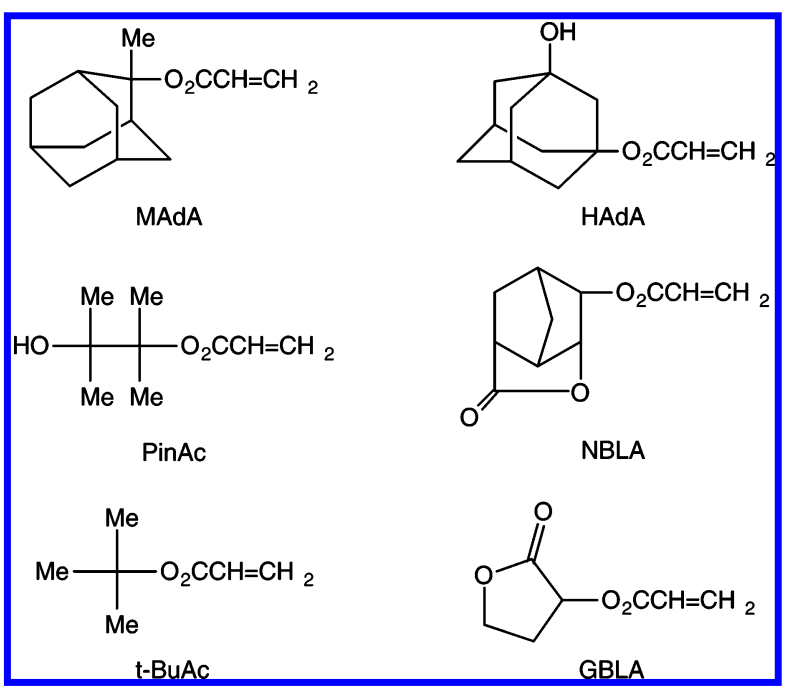

Figure 4. Acrylate monomers and abbreviations. Acid-labile solubility switch monomers in left column.

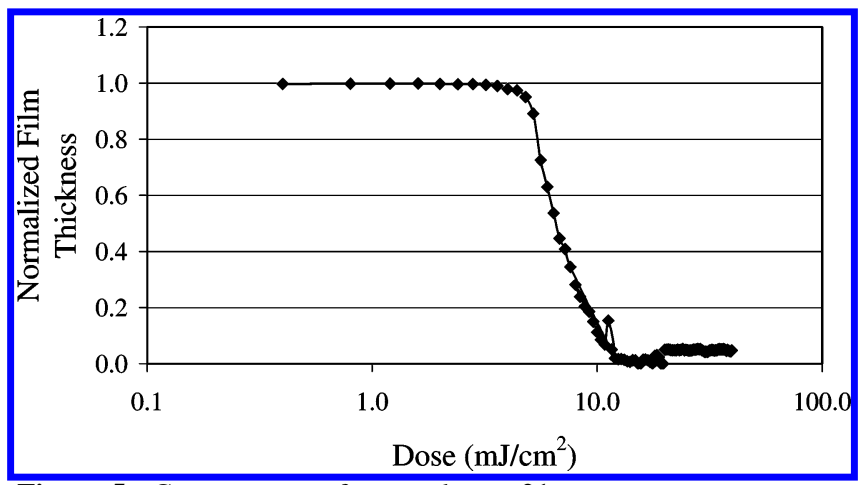

Figure 5. Contrast curve for terpolymer 21.

As with the TFE dipolymers described above, these terpolymers were prepared by batch copolymerizations, relying on the tendency of TFE and the polycyclic olefins to alternate to provide uniform compositions. Perkadox 16 (di-tert-butylcyclohexylperoxydicarbonate) was used as initiator except for polymers 23-2 and 23-3 for which bis[2,3,3,3-tetrafluoro-2(heptafluoropropoxy)-1-oxopropyl] peroxide (HFPO-dp) was used. As described elsewhere, the use of HFPO-dp leads to a
$0.2-0.3 \mu \mathrm{m}^{-1}$ improvement in $157 \mathrm{~nm}$ transparency because the latter initiator does not leave carbonyl-containing end groups on the polymer chains. ${ }^{11}$

Polymer compositions were generally determined by ${ }^{19} \mathrm{~F}$ NMR. For polymers $\mathbf{2 1}$ and 23, which lack fluorine signals from the TCN component, ${ }^{13} \mathrm{C}$ NMR spectra were obtained for complete compositional analysis using the carbonyl signal to quantify the TCN ester. Conversions calculated for the polycyclic monomers indicate that these TCN monomers generally have a reactivity slightly greater than that of the norbornene $\mathrm{NB}-\mathrm{F}-\mathrm{OH}$.

Polymers in this series show glass transition temperatures at $160-200{ }^{\circ} \mathrm{C}$. Thermal decomposition temperatures are significantly lower and more variable than found for the dipolymers described above due to the presence of tert-butyl ester groups. The TGA curves show distinctive weight losses at 190-270 ${ }^{\circ} \mathrm{C}$ with a maximum rate at about $240{ }^{\circ} \mathrm{C}$ which is ascribed to the loss of isobutylene.

Polymers from TFE, TCN, and Acrylates. Polymers comprising TFE and TCN monomers $\mathbf{1 a}, \mathbf{1 h}, \mathbf{1 p}, \mathbf{1 q}$, and $\mathbf{1 r}$ with various acrylates (Figure 4) and, in some cases, NB-F$\mathrm{OH}$ were prepared mainly for imaging at $193 \mathrm{~nm}$. Selected polymers are detailed in Table 3 . As described previously, ${ }^{6}$ the substantially higher reactivity of acrylates relative to the other monomers requires that these polymers be produced using a semibatch process to afford reasonably homogeneous compositions. In practice, the reactor was charged with half of the polycyclic olefin(s)/acrylate(s) mixture with the polycyclic olefin(s) being present in large excess (for example, a 92/8 ratio). The reactor was heated to $50{ }^{\circ} \mathrm{C}$, and an excess of TFE was added to the pressure indicated in column 3 . A constant pressure was maintained throughout the reaction by feeding TFE on demand. A more acrylate rich mixture (for example, 52/48 ratio) was then fed to the reactor. At the same time, a separate solution of the peroxydicarbonate initiator was fed in as detailed in the Experimental Section. After polymerization, the polymers were typically in solution as is or were in solution after addition of THF. The polymers were precipitated into excess heptane, redissolved in Solkane/THF, and precipitated again into heptane. After the preciptiates were dried in a vacuum oven, white powdery polymers were obtained with the gram yields indicated 


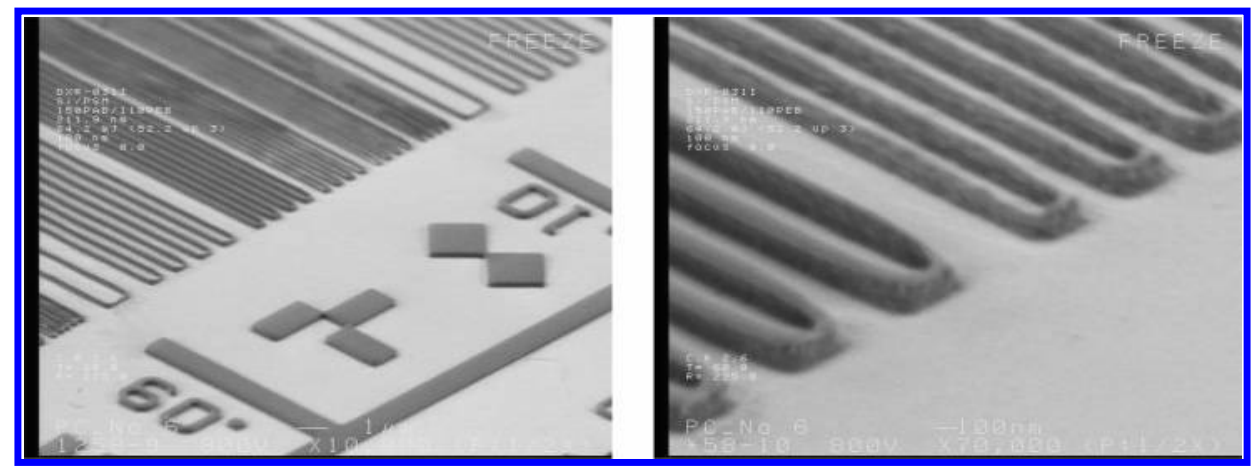

Figure 6. (left) $157 \mathrm{~nm}$ generated image of $100 \mathrm{~nm}$ lines and spaces with varying densities in a $212 \mathrm{~nm}$ thick film of terpolymer 21 using monomer

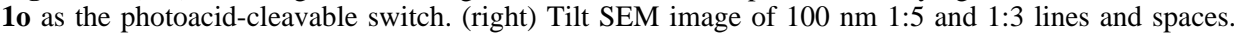

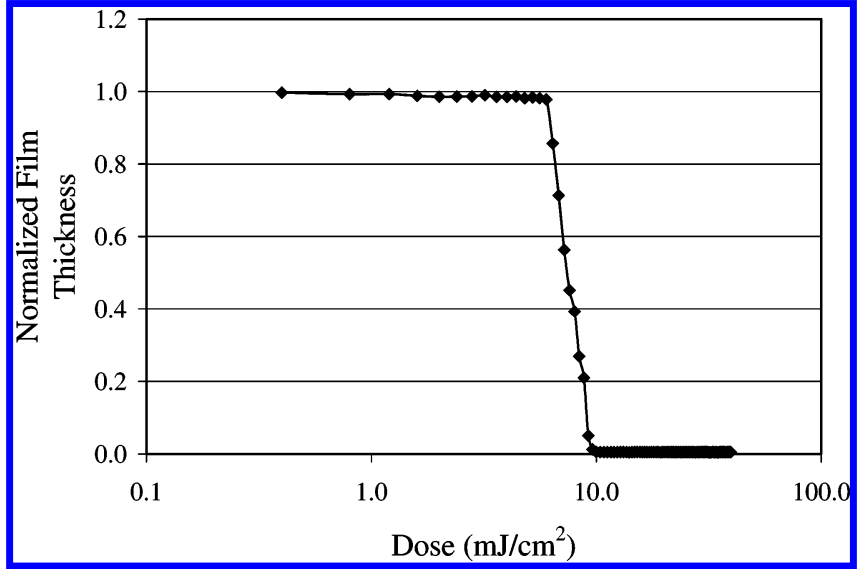

Figure 7. Contrast curve for polymer 23-3 formulated with $5 \mathrm{wt} \%$ TPS-Nf and 10 mol PAG \% TBALac. The dose to clear is slightly less than $10 \mathrm{~mJ} / \mathrm{cm}^{2}$.

in column 5. Polymer compositions were determined using a combination of ${ }^{19} \mathrm{~F}$ and ${ }^{13} \mathrm{C}$ NMR.

$1,1,1,3,3$-Pentafluorobutane was typically used as the polymerization solvent although some methyl acetate was introduced in the initiator feed stream due to the limited solubility of the initiator in the hydrofluorocarbon solvent. For polymers 3337, methyl acetate alone was employed as the polymerization solvent due to solubility issues with some of the acrylate monomers when used at high concentrations. Generally, the change from the pentafluorobutane to methyl acetate had little effect on yields and molecular weights in the high acrylate content polymers. Initial polymerization tests to prepare these relatively high acrylate content polymers afforded materials with molecular weights substantially above the desired 10-15000 $\left(M_{\mathrm{w}}\right)$ for the photoresist application. Addition of THF, typically $40 \mathrm{~mol} \%$ of the monomers (excluding TFE), lowered molecular weights to the desired range without negatively impacting conversion.

The acrylate monomers and their acronyms are shown in Figure 4. Those in the left column have acid labile alkyl groups which are readily cleaved by photogenerated acid so are considered to be switch monomers. The remaining esters are more stable to acid and are not believed to function as switch monomers but contribute a desirable measure of polarity and/or etch resistance to the compositions. With the exception of PinAc, the remaining acrylates have been previously used in chemically amplified photoresists. ${ }^{13-23}$ PinAc, whose synthesis is described in the Supporting Information, was developed by us as an alternative to $t$-BuAc. In principle, it provides greater polarity and a less volatile leaving group (pinacolone vs isobutylene).

Several aspects of the behavior of the TFE, polycyclic olefin, and acrylate polymerizations are apparent from inspection of Table 3. Polymers 24-1 to 24-4 illustrate a systematic increase in the acrylate content from 28 to $51 \%$ as the feed composition is made more acrylate rich and the TFE pressure is decreased. Acrylate mostly displaces TFE as might be expected considering monomer polarity. Also noted is the tendency for molecular weight to increase as the acrylate content increases despite the increase in initiator.

Acrylate conversion is uniformly higher than that of the polycyclic olefins; not surprising considering that acrylates readily homopolymerize whereas the polycyclic olefins do not under these free radical conditions. Polymers 30-1 and 30-2, which were prepared using an identical monomer feed but different initiator amounts, illustrate the expected increase in conversion and decrease in molecular weight as initiator amount is increased. Polymer compositions show a slight increase in total acrylate content at lower conversion suggesting that the semibatch feed process nearly but not completely corrects for differences in reactivity ratios.

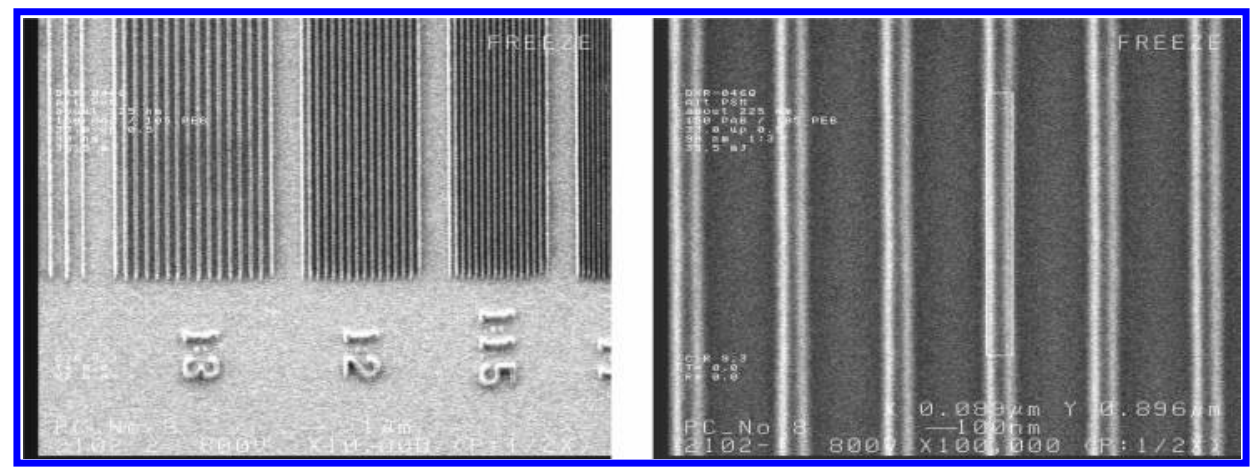

Figure 8. Top-down SEMs of 23-3 formulated with $5 \mathrm{wt} \%$ TPS $-\mathrm{Nf}$ and $10 \mathrm{~mol}$ PAG \% TBALac. The resin was polymerized using the HFPO-dp initiator to minimize $157 \mathrm{~nm}$ absorbance due to end groups. The film thickness was $225 \mathrm{~nm}$. On the left are shown 90 nm 1:3, 1:2 and 1:1.5 lines and spaces, and on the right $90 \mathrm{~nm} \mathrm{1:3} \mathrm{lines} \mathrm{and} \mathrm{spaces.} \mathrm{The} \mathrm{white} \mathrm{box} \mathrm{illustrates} \mathrm{the} \mathrm{proper} 90 \mathrm{~nm}$ feature size obtained at this exposure dose. 


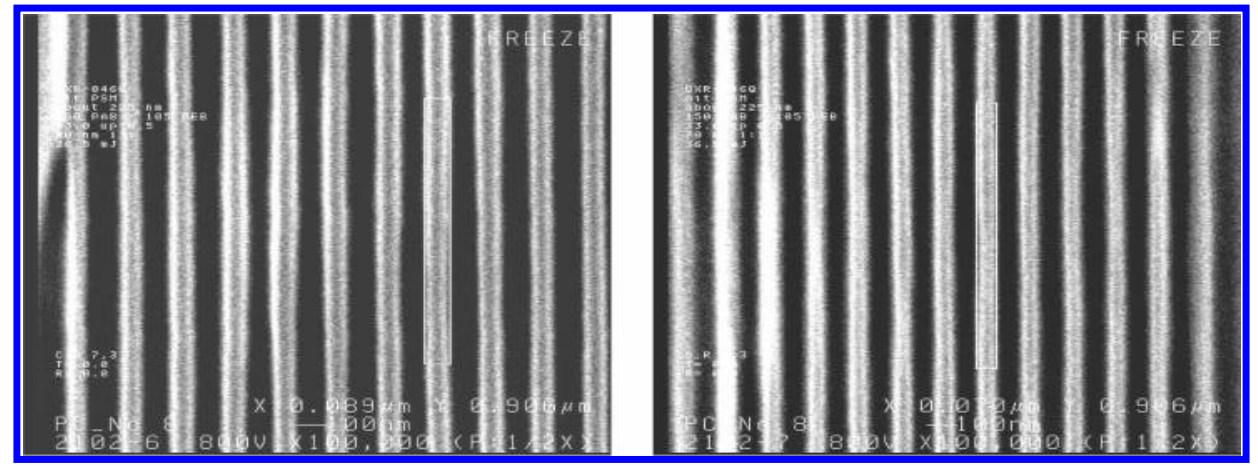

Figure 9. Top-down SEMs of polymer 23-3 formulated with 5 wt $\%$ TPS-Nf and 10 mol PAG \% TBALac. The resin was polymerized using the HFPO-dp initiator to minimize $157 \mathrm{~nm}$ absorbance due to end groups. The film thickness was $225 \mathrm{~nm}$. On the left we show $90 \mathrm{~nm}$ 1:1 lines and spaces, and on the right $70 \mathrm{~nm} \mathrm{1:1} \mathrm{lines} \mathrm{and} \mathrm{spaces.} \mathrm{The} \mathrm{white} \mathrm{boxes} \mathrm{illustrate} \mathrm{the} \mathrm{proper} 90$ and $70 \mathrm{~nm}$ feature sizes obtained at these exposure doses.

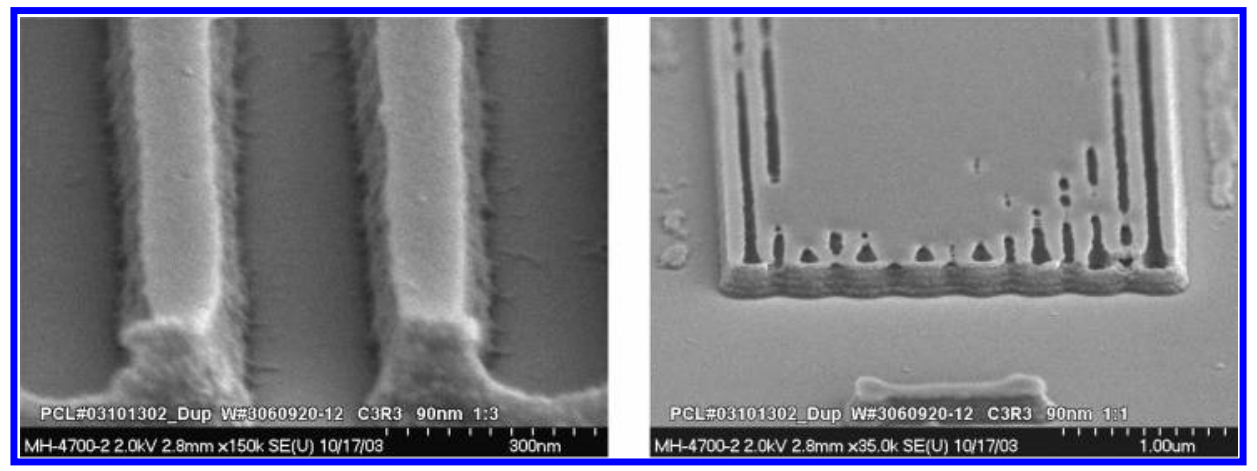

Figure 10. Cross-section SEMs of polymer 23-3 formulated with $5 \mathrm{wt} \%$ TPS-Nf and 10 mol PAG \% TBALac. On the left are shown $90 \mathrm{~nm} \mathrm{1:3}$ lines and spaces, and on the right are shown $90 \mathrm{~nm} \mathrm{1:1} \mathrm{lines} \mathrm{and} \mathrm{spaces} \mathrm{that} \mathrm{have} \mathrm{only} \mathrm{partially} \mathrm{cleared} \mathrm{at} \mathrm{this} \mathrm{exposure} \mathrm{dose,} \mathrm{perhaps} \mathrm{as} \mathrm{a} \mathrm{result}$ of T-topping due to some environmental contamination. The presence of standing waves can also be clearly seen on the sides of the line profiles in the figure on the right.

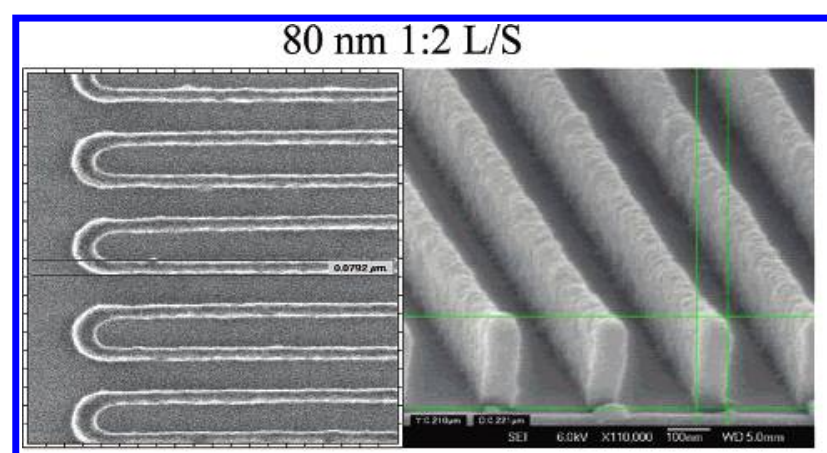

$100 \mathrm{~nm} \mathrm{1:1} \mathrm{L/S}$

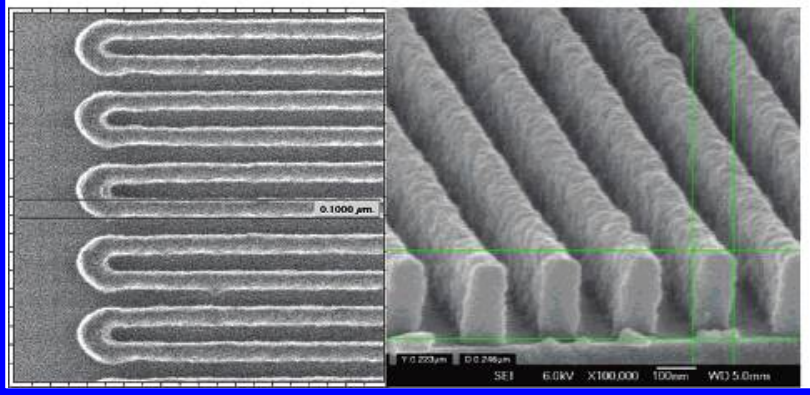

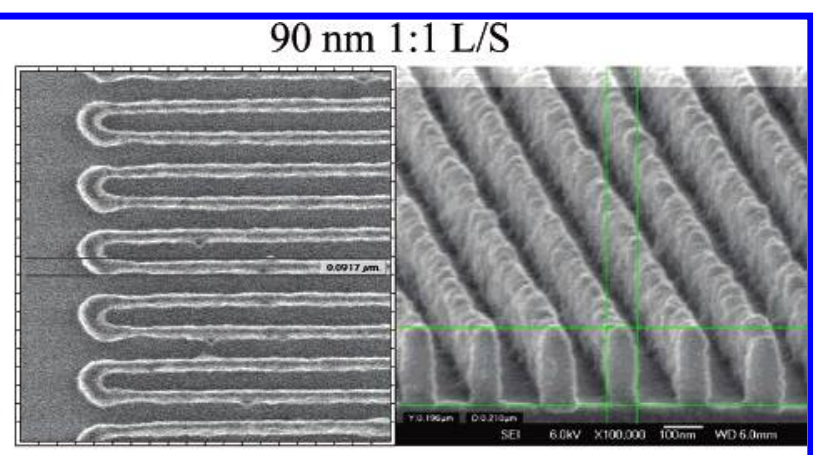

$100 \mathrm{~nm} 1: 1.5 \mathrm{~L} / \mathrm{S}$

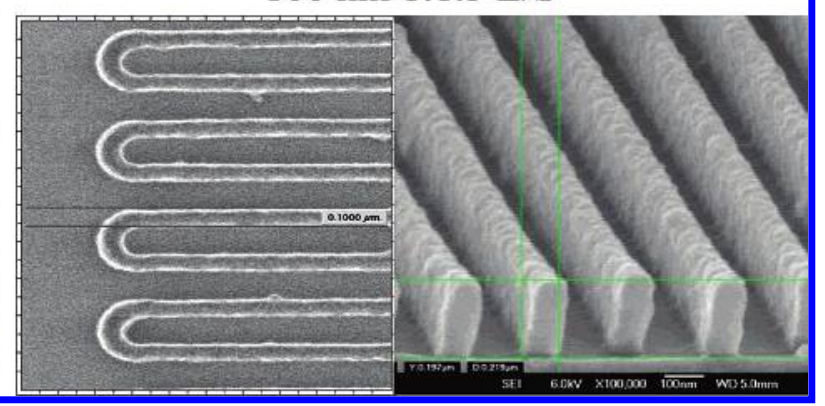

Figure 11. SEM pictures of tetrapolymer 30-1 demonstrating dense and semidense lines.

Polymers 30-39 use the TCN diesters $1 q$ or $1 \mathbf{r}$ and a variety of acrylates so some or all of the acid-labile solubility switch is incorporated into the polycyclic olefin framework. Comparisons of 30-1 and 39-1 indicate little difference between the behaviors of the trans and cis isomers during polymerization.
In all cases the polymers were obtained as white solids which are freely soluble in standard, moderately polar organic solvents such as THF, acetone, and 2-heptanone and insoluble in hydrocarbons. Glass transition temperatures are reported for many of the polymers in Table 3, but they often were difficult or impossible to detect by DSC, probably due to their proximity 


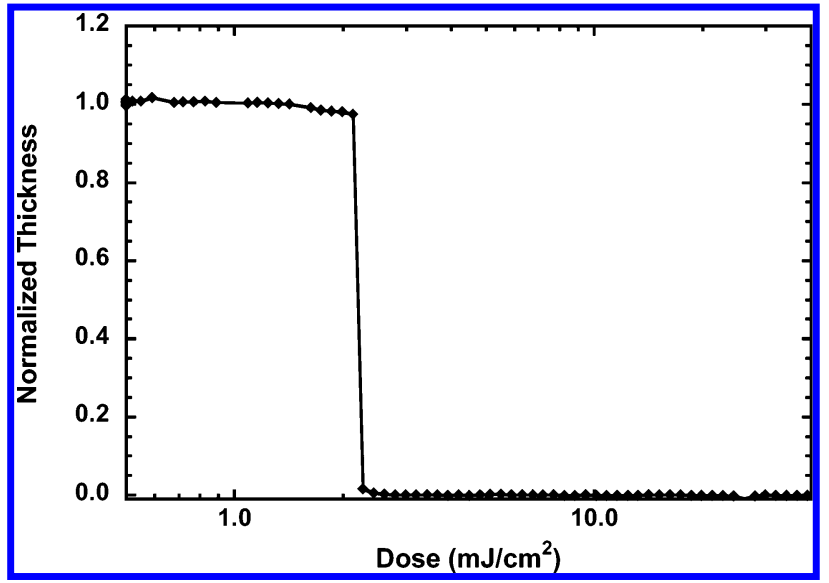

Figure 12. Contrast curve of a tetrapolymer 30-1 showing a sharp distinction between developed resist and undeveloped resist at a certain exposure dose.

to the onset of thermal decomposition. As noted for the polymers in Table 2, the initial weight loss detected by TGA is due to thermal loss of the acid-labile protecting groups in the polymer side chains.

Imaging of TCN Fluoropolymers Using 157 nm Radiation. A number of the fluoropolymers described in this paper were evaluated for $157 \mathrm{~nm}$ lithographic imaging at International Sematech.

In Figure 5, we show the $157 \mathrm{~nm}$ contrast curve for polymer 21, containing $29 \%$ of the TCN monoester 1o, formulated with 5 wt $\%$ triphenylsulfonium nonaflate (TPS-Nf) PAG and 10 PAG mol \% tetrabutylammonium lactate (TBALac) base. The dose-to-clear is approximately $10 \mathrm{~mJ} / \mathrm{cm}^{2}$, which is a fairly low value indicating good photosensitivity. The contrast is not very high, however, suggesting that this particular resin will not image dense features very well.

Although the imaging of this TCN terpolymer with the monoester switch shown in Figure 6 was acceptable, we were very interested to investigate the imaging of copolymers that instead incorporated a TCN diester as the photoactive switch, as for example monomers $\mathbf{1 q}$ or $\mathbf{1 r}$ in Figure 3.
In Figure 7, we show the $157 \mathrm{~nm}$ contrast curve of a terpolymer 23-3 which incorporated $10 \mathrm{~mol} \%$ of the trans isomer 1q and exhibited a formulated $157 \mathrm{~nm}$ optical absorbance of $1.71 \mu \mathrm{m}^{-1}$. The dose to clear for this copolymer is slightly less than $10 \mathrm{~mJ} / \mathrm{cm}^{2}$, rather similar to that of the terpolymer with the TCN monoester. This is interesting since the terpolymer with the diester has less protected carboxylic acid (20\%) than the terpolymer with the monoester $(30 \%)$. This observation suggests that there is some synergy in placing two protected acids on one monomer, perhaps facilitating the deprotection by the photoacid. We also note that the dissolution contrast of this diester terpolymer is considerably higher than that of the TCN monoester terpolymer, which should be reflected in improved imaging, particularly for dense features.

In Figure 8, we show $157 \mathrm{~nm}$ imaging of semidense $90 \mathrm{~nm}$ lines and spaces of varying pitch for this terpolymer. The imaging is fairly good, considering that the $157 \mathrm{~nm}$ optical absorbance is still rather high, $1.71 \mu \mathrm{m}^{-1}$, although considerably less than that of the TCN monoester described above. In Figure 9, we show images of 90 and $70 \mathrm{~nm} \mathrm{1:1} \mathrm{dense} \mathrm{lines}$ and spaces. This terpolymer is clearly capable of resolving these features, consistent with the high contrast of the resist. In Figure 10, we show cross sections SEM images for this resist that show a propensity toward T-topping, presumably due to some environmental contamination during the lithographic processing.

The TCN copolymers thus show reasonably good imaging at $157 \mathrm{~nm}$, consistent with their fairly high dissolution contrast. Their $157 \mathrm{~nm}$ optical absorption is, however, not as low as one would wish for a resist resin due to the presence of carbonyls in the carboxylic acid groups used as the photoacid-cleavable switches. Replacing the carboxylic acid groups with protected fluoro alcohols is a possible route to improved $157 \mathrm{~nm}$ transparency that we have briefly explored, but in that case, it also appears necessary to fully fluorinate the four-membered ring in the TCN monomer, such as in monomer $\mathbf{1 g}$ in Figure 3. More work in this direction would be of value if $157 \mathrm{~nm}$ lithography ever returns to the International Sematech road map as a potential technology.
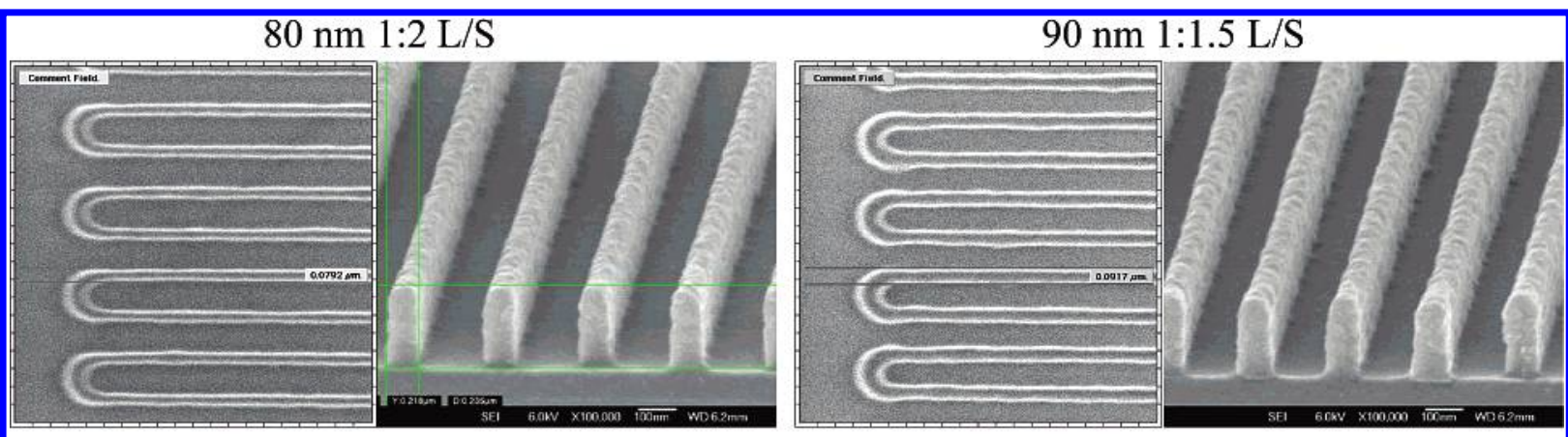

$100 \mathrm{~nm} 1: 1.5 \mathrm{~L} / \mathrm{S}$

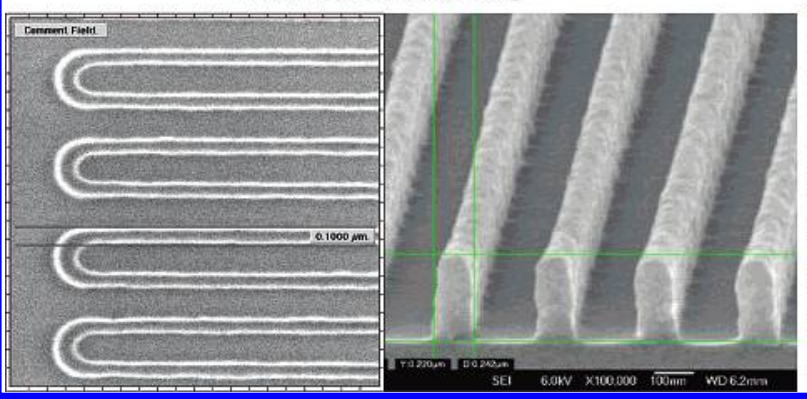

$100 \mathrm{~nm} \mathrm{1:2} \mathrm{L/S}$

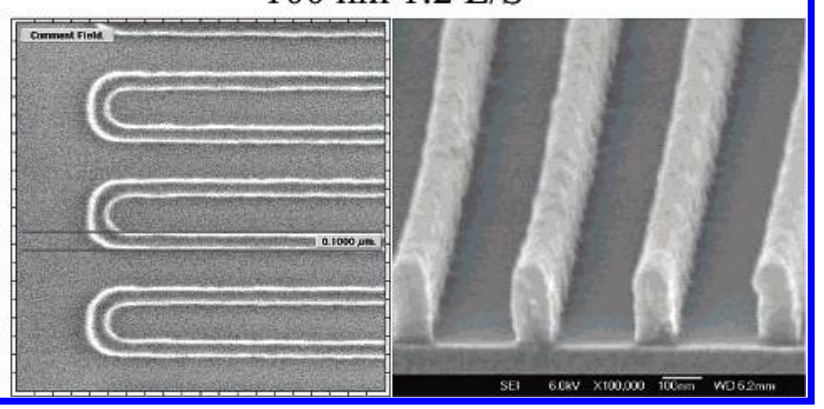

Figure 13. SEM pictures of a tetrapolymer $\mathbf{2 8}$ demonstrating dense and semidense lines. 


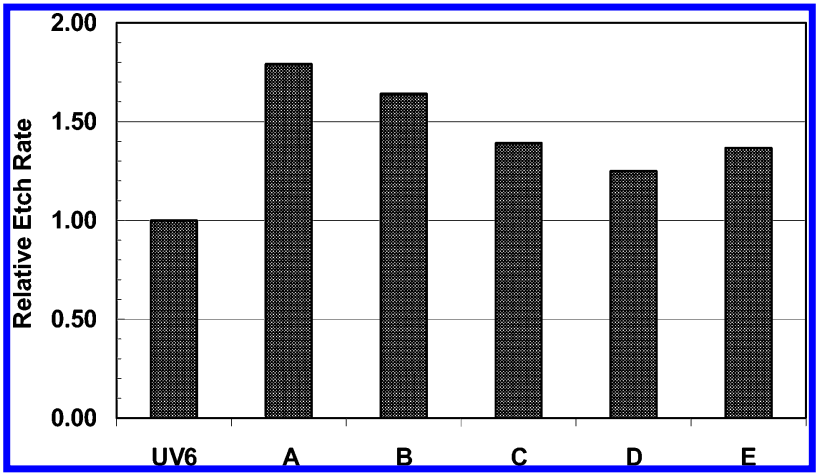

Figure 14. Relative oxide etch rates for five polymers as compared to UV6. TCN-containing polymers show lower etch rates than comparable norbornene-containing polymers. $\mathrm{A}=\mathrm{TFE} / \mathrm{NB}-\mathrm{F}-\mathrm{OH}$, $\mathrm{B}=\mathrm{TFE} / \mathbf{1 h}, \mathrm{C}=\mathrm{TFE} / \mathrm{NB}-\mathrm{F}-\mathrm{OH} / \mathrm{PinAc} / \mathrm{HAdA}, \mathrm{D}=\mathrm{TFE} / \mathbf{1 h} / \mathrm{PinAc} /$ $\mathrm{HAdA}$, and $\mathrm{E}=\mathrm{TFE} / \mathrm{NB}-\mathrm{F}-\mathrm{OH} / \mathbf{1 q} / \mathrm{HAdA}$.

Imaging of TCN Fluoropolymers Using 193 nm Radiation. Many copolymers containing TFE and a TCN monomer with or without a norbornyl fluoro alcohol monomer and a number of acrylates were lithographically evaluated using $193 \mathrm{~nm}$ light. The polymer is typically formulated with triphenylsulfonium nonaflate as the photoacid generator and tetrabutylammonium lactate as the base, is dissolved in a suitable solvent such as 2-heptanone, coated onto a silicon wafer to obtain $270 \mathrm{~nm}$ of film thickness, and imaged using an SVG Micrascan 193 stepper fitted with a phase-shift mask.

These TFE/TCN-based polymers show promising $193 \mathrm{~nm}$ imaging. An example is the TFE tetrapolymer 30-1 made from 1q, a norbornyl fluoro alcohol monomer, and a hydroxyadamantyl acrylate. The top-down and cross-sectional SEMs of this polymer demonstrating $90 \mathrm{~nm}$ dense lines, as well as 80 and $100 \mathrm{~nm}$ dense and/or semidense lines, is shown in Figure 11. The contrast curve, plotting normalized film thickness vs exposure dose, is fairly sharp (Figure 12), possibly due to the clustering of two acid-cleavable tert-butyl ester groups on one TCN monomer unit.

In polymer 28, a fluoro alcohol is incorporated into the TCN unit itself (1h), and the acid-cleavable group is added as an acrylate (PinAc). The SEM profiles obtained from this polymer are shown in Figure 13. The absorption was measured to be $0.168 \mu \mathrm{m}^{-1}$ (at $193 \mathrm{~nm}$ ) for this polymer. Absorptions below $0.3 \mu \mathrm{m}^{-1}$ are typical for all the TCN-containing fluoropolymers. These images and data show that TFE/TCN copolymers are capable of high-resolution imaging at $193 \mathrm{~nm}$ lithography.

When compared to similar polymers containing norbornene compounds, these TCN-containing polymers show better oxide etching resistance. In several cases, we have seen that the TCN compounds provide from 10 to $20 \%$ reduction in oxide etch rate. Figure 14 shows relative etch rates using a blanket oxide etch recipe for five polymers and UV6, an industry-standard resist polymer with one of the lowest oxide etch rates. The best TCN polymer in this group shows etch resistance that is 1.25 times that of UV6.

\section{Conclusions}

We have shown that a wide variety of tricyclononenes with substituents in the 3 and 4 positions readily form dipolymers with TFE, and ter-, tetra, and pentapolymers with TFE, other polycyclic olefins and/or various acrylates under standard free radical conditions. The resulting polymers are amorphous, have good thermal stability, have glass transition temperatures generally in excess of $150{ }^{\circ} \mathrm{C}$, and are soluble in standard organic solvents even with a fluorine content as high as $50 \mathrm{~mol}$
$\%$. A wide range of functionality can be incorporated by varying the TCN or acrylate monomers. Many TCN monomers are easily prepared in one to a few steps from commercially available starting materials and are generally as reactive as or more reactive than norbornenes in polymerizations with TFE. Incorporation of acrylates complicates the polymerization process due to differences in reactivity ratios but this can be overcome with a relatively simple semibatch polymerization process.

We have demonstrated successful image formation at both 157 and $193 \mathrm{~nm}$ with selected TFE/TCN polymers using the standard chemically amplified imaging process and aqueous development. We have also shown that replacement of norbornene-based components with TCN groups can lead to improved ion etch resistance.

Although impetus for this work came mainly from a search for the best polymers for semiconductor processing, the properties of the TFE/TCN copolymers suggest applications in other technology areas, especially ones involving optics or electronics. The materials to date have been prepared with relatively low molecular weights $\left(M_{\mathrm{w}}\right.$ in the 10-20 000 range) because this is regarded as ideal for photoresists and may be useful for other thin film applications. Other applications such as those using free-standing films may require higher molecular weights and we are working to achieve them by modification of the polymerization process and chain extension or cross-linking after polymerization.

\section{Experimental Section}

Caution! Tetrafluoroethylene is a deflagrating explosive and a cancer suspect agent. All work with TFE is conducted in barricaded facilities which would contain an explosion of this monomer. Reactor controls are located outside the barricade and no one is permitted to enter during operations when TFE is present.

Materials. The acrylate monomers MAdA and HAdA were obtained from Idemitsu, NBLA from Daychem, GBLA from Kuraray, and $t$-BuAc from Aldrich. All were used as received except for $t$-BuAc which was passed through a short alumina column immediately prior to polymerization. Norbornadiene was obtained from either Aldrich or Clariant. Trifluoromethylacrylic acid and trifluoromethyltrimethylsilane were obtained from Synquest Laboratories. Quadricyclane was obtained from Aldrich or Exciton. $\mathrm{Nb}-$ $\mathrm{F}-\mathrm{OH}^{6}$ and $\mathrm{NB}-\mathrm{di}-\mathrm{F}-\mathrm{OH}^{11}$ (1i) were prepared as described previously.

Methods. GPC analyses were done using an Alliance 2690 instrument from Waters Corporation (Milford, MA), with a Waters 410 refractive index detector (DRI). Two PL Gel Mixed C and one PL Gel 500A columns from Polymer Laboratories were used for separation with unstabilized THF as the mobile phase. Typical chromatographic conditions were as follows: temperature, $40{ }^{\circ} \mathrm{C}$; flow rate, $1.00 \mathrm{~mL} / \mathrm{min}$; injection volume, $100 \mu \mathrm{L}$; run time, 35 min. A conventional calibration method with narrow MW polystyrene standards was used.

${ }^{13} \mathrm{C}$ NMR and ${ }^{19} \mathrm{~F}$ spectra were obtained on a Varian Inova 400 $\mathrm{MHz}$ spectrometer using a $5 \mathrm{~mm}$ quad-nucleus probe $(1 \mathrm{H}, 19 \mathrm{~F}$, $13 \mathrm{C}, 31 \mathrm{P}$ ) for carbon and a $5 \mathrm{~mm} \mathrm{H}-\mathrm{F}$ probe for fluorine. The carbon-13 frequency was $100.577 \mathrm{MHz}$ and the fluorine-19 frequency was $376.3 \mathrm{MHz}$. When the samples were run in methylene choride- $d_{2}$, the temperature was set at $30{ }^{\circ} \mathrm{C}$, and when run in dimethyl sulfoxide- $d_{6}$, it was set to $60{ }^{\circ} \mathrm{C}$. In the case of carbon-13 NMR, about 200-300 mg of sample was dissolved in the appropriate solvent with chromium(III) acetylacetonate (Cr$(\mathrm{AcAc})$ ) (about $25 \mathrm{mg}$ ) added to shorten the relaxation time. For fluorine-19 NMR about $100 \mathrm{mg}$ of sample was dissolved in the appropriate solvent. The carbon chemical shifts were referenced to TMS and the fluorine shifts were referenced to $\mathrm{CCl}_{3} \mathrm{~F}$. The quantitative ${ }^{19} \mathrm{~F}$ spectra were obtained using a standard Varian s2pul sequence with a $90^{\circ}$ pulse angle whose pulse width was about 5 $\mu \mathrm{s}$, a repetition time of $7 \mathrm{~s}$, about $8 \mathrm{~T} 1$ 's, and an acquisition time 
of $1.311 \mathrm{~s}$. The spectral width was set to $89686 \mathrm{~Hz}$, and the number of points used to acquire the data was $256 \mathrm{~K}$, which was zero-filled when processed. To ensure good integrals, the baseline was flattened by setting the pre-acquisition delay (rof2) to 1 or 2 and then setting the $\alpha$ delay by using the calfa macro. If needed, to flatten the baseline further a linear prediction was done using the first two to three points. In processing the data, an exponential multiplication with $\mathrm{LB}=7$ was used. The quantitative ${ }^{13} \mathrm{C}$ spectra with $\mathrm{Cr}-$ (AcAc) added were obtained using the standard s2puls sequence with inverse gated Waltz ${ }^{1} \mathrm{H}$ decoupling (decoupler on during acquisition time), using $90^{\circ}$ pulse angle whose pulse-width was about $11-13 \mu \mathrm{s}$, a repetition time of $10 \mathrm{~s}$, and an acquisition time of $2.785 \mathrm{~s}$. The spectral width was set to $13000 \mathrm{~Hz}$ using $256 \mathrm{~K}$ points, which was then zero-filled when processed. If needed the baseline was flattened using the procedure given above. In processing the data, an exponential multiplication with $\mathrm{LB}=10$ was used.

Glass transition temperatures were obtained using a TA Instruments Q1000 MDSC. Samples were run in the modulated mode under the following conditions using standard DSC pans in a nitrogen atmosphere: data storage off; equilibrate at $-50.00{ }^{\circ} \mathrm{C}$; modulate $\pm 0.50{ }^{\circ} \mathrm{C}$ every $40 \mathrm{~s}$; isothermal for $5.00 \mathrm{~min}$; data storage, on; ramp $5.00{ }^{\circ} \mathrm{C} / \mathrm{min}$ to $250.00{ }^{\circ} \mathrm{C}$.

Decomposition temperatures are reported at the temperature of $10 \%$ weight loss under nitrogen as determined using a TA Instruments Q500 TGA. Samples were equilibrated at $30^{\circ} \mathrm{C}$ and then ramped $20^{\circ} \mathrm{C} / \mathrm{min}$ to $650^{\circ} \mathrm{C}$.

Vacuum ultraviolet (VUV) transmission measurements were made using a double-beam McPherson spectrometer equipped with a deuterium lamp. Each resist sample was spin-cast at two different film thicknesses on $\mathrm{Si}$ substrates to determine the resist spin curve. The resists were then spin-coated on $\mathrm{CaF}_{2}$ substrates at the appropriate speeds to obtain film thickness from 50 to $200 \mathrm{~nm}$. The transmission spectra of the films were then measured, and the results divided by the transmission of the uncoated $\mathrm{CaF}_{2}$ substrates to obtain the final transmission spectra. The transmission spectra were converted to absorbance spectra by using the relation $A_{157}$ $\left(\mu \mathrm{m}^{-1}\right)=\log (1 / T) / \mathrm{FT}$, where $T$ is the transmittance of the film and FT is the film thickness in micrometers. Optical absorbance measurements were also performed at International Sematech using vacuum ultraviolet variable angle spectral ellipsometry (Woollam VUVvase). Resist or polymer films were spin-cast on Si wafers and measured in reflectance. The resulting amplitude and phase data were converted to index of refraction and absorption coefficient data by standard fitting procedures.

Polymers described were evaluated for $157 \mathrm{~nm}$ lithographic imaging at International Sematech using the Exitech stepper equipped with Tropel optics. Images were collected with 0.6 or 0.85 numerical aperture (NA) optics using a binary $(\sigma=0.7)$ or alternating $(\sigma=0.3)$ phase shift mask. Formulated resist films were coated on Si wafers, or in some cases on an organic (Shipley AR19) or an inorganic (SiON) antireflective coating (ARC), postapply baked (PAB) at temperatures between 120 and $150{ }^{\circ} \mathrm{C}$ for $60 \mathrm{~s}$, then imaged on the stepper. After exposure, the resist films were postexposure baked (PEB) at temperatures between 90 and $150{ }^{\circ} \mathrm{C}$ for $60 \mathrm{~s}$, and then puddle developed using Shipley MF-26A or LDD$26 \mathrm{~W}$ for $60 \mathrm{~s}$. The resulting images were examined using a JEOL JWS 7550 scanning electron microscope (SEM) or a KLA Tencor 8100 XP. Cross-sections were measured at International Sematech using a Hitachi 4500 SEM.

Typical Batch Polymerization. Synthesis of Polymer 3. A 200 $\mathrm{mL}$ stainless steel pressure vessel was charged with $47.0 \mathrm{~g}(0.245$ mol) of 1a, $30 \mathrm{~mL}$ of Solkane $365 \mathrm{mfc}$ and $2.23 \mathrm{~g}$ of Perkadox 16 $\mathrm{N}$ initiator. The vessel was closed, cooled in dry ice, purged with nitrogen, evacuated, and charged with $45.5 \mathrm{~g}(0.455 \mathrm{~mol})$ of TFE. The vessel was then agitated with its contents at $50{ }^{\circ} \mathrm{C}$ for $18 \mathrm{~h}$ while the internal pressure decreased from 361 to 321 psi. The vessel was cooled to room temperature and vented to $1 \mathrm{~atm}$. The vessel contents were recovered using additional Solkane for rinsing. The combined solutions were added to excess hexane (20:1 by volume). The solid was filtered, washed with hexane, and allowed
Table 4. Photoresist Formulation for 157 and 193 nm Imaging

\begin{tabular}{|c|c|}
\hline component & wt (g) \\
\hline $\begin{array}{l}157 \mathrm{~nm} \text { Imaging } \\
\text { TFE/NB-F-OH/1q 48/42/10 } \\
\quad(\text { Table } 2-\text { polymer } 23-3 \text { ) }\end{array}$ & 1.938 \\
\hline $\begin{array}{l}\text { 2-heptanone } \\
\text { solution of tetrabutylammonium lactate in 2-heptanone } \\
\text { prepared as follows: } 2.5 \mathrm{gm} \text { of aqueous } \\
\text { tetrabutylammonium hydroxide ( } 40 \% \text {, Sigma-Aldrich } \\
\text { Chemical Co.) was dissolved in } 97.5 \text { gm ethyl lactate } \\
\text { (Sigma-Aldrich Chemical Co.). } 6.0 \text { gm of this } \\
\text { solution was later dissolved in } 6.0 \text { gm of 2-heptanone. }\end{array}$ & $\begin{array}{l}12.356 \\
1.210\end{array}$ \\
\hline $\begin{array}{l}6.82 \mathrm{wt} \% \text { solution of triphenylsulfonium nonaflate } \\
\text { dissolved in } 2 \text {-heptanone that had been filtered } \\
\text { through a } 0.45 \mu \mathrm{m} \text { PTFE syringe filter. }\end{array}$ & 1.496 \\
\hline $\begin{array}{l}193 \mathrm{~nm} \text { Imaging } \\
\text { TFE/NB-F-OH/1q/HAdA } \\
\text { 29/38/10/24 (Table } 3 \text { - polymer 30-2) }\end{array}$ & 2.940 \\
\hline $\begin{array}{l}\text { 2-heptanone } \\
\text { solution of tetrabutylammonium lactate in 2-heptanone } \\
\text { prepared similarly to that for } 157 \mathrm{~nm} \text { formulation. }\end{array}$ & $\begin{array}{l}20.460 \\
0.72\end{array}$ \\
\hline $\begin{array}{l}6.82 \mathrm{wt} \% \text { solution of triphenylsulfonium nonaflate } \\
\text { dissolved in } 2 \text {-heptanone that had been filtered } \\
\text { through a } 0.45 \mu \mathrm{m} \text { PTFE syringe filter. }\end{array}$ & 0.880 \\
\hline
\end{tabular}

to air-dry for several hours. The solid was further dried in a vacuum over overnight at $88-90^{\circ} \mathrm{C}$. The isolated yield was $49.2 \mathrm{~g}$ of white polymer. GPC analysis: $M_{\mathrm{n}} 8700 ; M_{\mathrm{w}} 20600 .{ }^{19} \mathrm{~F}$ NMR $(\delta$, THF$\left.d_{8}\right)-124.5$ (dd, $2 \mathrm{~F}$ from 1a), -95 to -124 (4F from TFE, $2 \mathrm{~F}$ from 1a). By integration, the polymer composition was calculated to be 49\% TFE and 51\%. Anal. Found: C, 46.97; H, 3.05; F, 46.05.

Typical Semibatch Polymerization: Synthesis of Polymer 241. A $300 \mathrm{~mL}$ Hastelloy vertical autoclave was purged with nitrogen and charged with $46.08 \mathrm{~g}(0.24 \mathrm{~mol})$ of $1 \mathrm{a}, 1.28 \mathrm{~g}(0.01 \mathrm{~mol})$ of

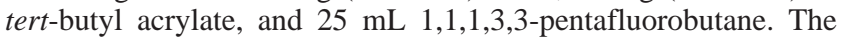
vessel was closed and cooled to $-15^{\circ} \mathrm{C}$. It was pressured with nitrogen to $400 \mathrm{psi}$ and vented twice. A slight vacuum was pulled. The reactor contents were agitated using a mechanical propeller and were heated to $50{ }^{\circ} \mathrm{C}$. The reactor was charge with TFE to a pressure of 320 psi. Controls were set to maintain this pressure throughout the polymerization by feeding TFE on demand. A solution prepared by diluting $50.0 \mathrm{~g}$ of $\mathbf{1 a}$ and $11.11 \mathrm{~g}$ of tertbutyl acrylate to $100 \mathrm{~mL}$ with 1,1,1,3,3-pentafluorobutane was fed to the reactor at $0.10 \mathrm{~mL} / \mathrm{min}$ for $12 \mathrm{~h}$. Simultaneously, a solution prepared by diluting $4.5 \mathrm{~g}$ Perkadox $16 \mathrm{~N}$ and $60 \mathrm{~mL}$ of methyl acetate to $100 \mathrm{~mL}$ with 1,1,1,3,3-pentafluorobutane was fed to the reactor at $2.0 \mathrm{~mL} / \mathrm{min}$ for $6 \mathrm{~min}$ and then at $0.1 \mathrm{~mL} / \mathrm{min}$ for $8 \mathrm{~h}$. The TFE feed was stopped when the monomer feed was stopped, and the reactor was maintained with agitation and at temperature for an additional $4 \mathrm{~h}$. It was then cooled to room temperature and vented. The vessel contents were recovered using additional 1,1,1,3,3-pentafluorobutane as needed to rinse. Polymer was precipitated by adding the solution to a 20 -fold excess of heptane while stirring. (Caution! Guard against static electricity discharges by appropriate grounding during this process.) The precipitate was filtered, air-dried, dissolved in a mixture of THF and 1,1,1,3,3-pentafluorobutane and reprecipitated into heptane. The filtered polymer was air-dried and then dried overnight in a vacuum oven at about $90{ }^{\circ} \mathrm{C}$. The yield was $27.8 \mathrm{~g} .{ }^{19} \mathrm{~F} \mathrm{NMR}\left(\delta, \mathrm{CD}_{2} \mathrm{Cl}_{2}\right)$ : -124.5 ( $2 \mathrm{~F}$ from $1 \mathrm{a}$ ), -95 to -123 (4F from TFE and $2 \mathrm{~F}$ from 1a). ${ }^{13} \mathrm{C}$ NMR $\left(\delta, \mathrm{CD}_{2} \mathrm{Cl}_{2}\right)$ (selected absorptions used for analysis): $105-125$ (2C from TFE and $2 \mathrm{C}$ from 1a), 166 , and $174(\mathrm{C}=$ O from acrylate). Anal: Found: C, 51.60; H, 4.55; F, 35.43.

Typical Formulation for Imaging. Representative photoresist formulations for 157 and $193 \mathrm{~nm}$ imaging are provided in Table 4

Acknowledgment. We thank the International Sematech 157 $\mathrm{nm}$ Resist Test Center for providing facilities and assistance in obtaining the $157 \mathrm{~nm}$ imaging results.

Supporting Information Available: Text giving detailed synthetic procedures and characterization data on monomers 1a-r, 2d, and PinAc and characterization data on polymers described in 
Tables 1, 2, and 3 and the appropriate references. This material is available free of charge via the Internet at http://pubs.acs.org.

\section{References and Notes}

(1) Feiring, A. E. in Banks, R. E.; Smart, B. E.; Tatlow, J. C.; Eds. In Organofluorine Chemistry. Principles and Commercial Applications; Plenum Press: New York, 1994; Chapter 15.

(2) Logothetis, A. L. In Organofluorine Chemistry. Principles and Commercial Applications; Banks, R. E., Smart, B. E., Tatlow, J. C., Eds.; Plenum Press: New York, 1994; Chapter 16.

(3) Resnick, P. R.; Buck, W. H. In Modern Fluoropolymers; Scheirs, J., Ed.; Wiley: New York, 1997; Chapter 22.

(4) Sugiyama, N. In Modern Fluoropolymers; Scheirs, J., Ed.; Wiley: New York, 1997; Chapter 28.

(5) Crawford, M. K.; Feiring, A. E.; Feldman, J.; French, R. H.; Periyasamy, M.; Schadt, F. L., III; Smalley, R. J.; Zumsteg, F. C., Jr.; Kunz, R. R.; Rao, V.; Liao, L.; Holl, S. M. Proc. SPIE-Int. Soc. Opt. Eng. 2000, 399 (Part 1, Advances in Resist Technology and Processing XVII), 357-364.

(6) Feiring, A. E.; Crawford, M. K.; Farnham, W. B.; Feldman, J.; French, R. H.; Leffew, K. W.; Petrov, V. A.; Schadt, F. L.; Wheland, R. C.; Zumsteg, F. C. J. Fluorine Chem. 2003, 122, 11

(7) Feiring, A. E.; Feldman, J. US Patent 6,593,058, 2003.

(8) Feiring, A. E.; Feldman, J.; Schadt, F. L., III. US Patent 6,790,587, 2004

(9) Ito, H.; Wallraff, G. M.; Fender, N.; Brock, P. J.; Hinsberg, W. D.; Mahorowala, A.; Larson, C. E.; Truong, H. D.; Breyta, G.; Allen, R. D. J. Vac. Sci. Technol. B 2001, 19, 2678.

(10) Bae, Y. C.; Douki, K.; Yu, T.; Dai, J.; Schmaljohann, D.; Koerner, H.; Ober, C. Chem. Mater. 2002, 14, 1306.

(11) Feiring, A. E.; Crawford, M. K.; Farnham, W. B.; French, R. H.; Leffew, K. W.; Petrov, V. A.; Schadt, F. L., III; Tran, H. V.; Zumsteg, F. C. Macromolecules 2006, 39, 1443.

(12) Reichmannis, E.; Nalamasu, O.; Houlihan, F. M. Acc. Chem. Res. 1999, $32,659$.

(13) Yamana, M.; Hirano, Masumi; Nagahara, Seiji; Kasama, Kunihiko; Hada, Hideo; Miyairi, Miwa; Kohno, Shinichi; Iwai, T. Proc. SPIEInt. Soc. Opt. Eng. 2003, 5039 (Part 2, Advances in Resist Technology and Processing XX), 752-760.

(14) Fedynyshyn, T. H.; Kunz, R. R.; Sinta, R. F.; Sworin, M.; Mowers, W. A.; Goodman, R. B.; Cabral, A. J. Photopolvm. Sci. Technol. 2002, $15,655-666$.

(15) Uetani, Y.; Fujishima, H. Proc. SPIE-Int. Soc. Opt. Eng. 2000, 3999 (Part 2, Advances in Resist Technology and Processing XVII), 974979.

(16) Shida, N.; Ushirogouchi, T.; Asakawa, K.; Okino, T.; Saito, S.; Funaki, Y.; Takaragi, A.; Tsutsumi, K.; Inoue, K.; Nakano, T. J. Photopolvm. Sci. Technol. 2000, 13 (4), 601-606.

(17) Chang, S.-Y.; Cheng, K.-L.; Ho, B.-C.; Chang, J.-F.; Chen, J.-H.; Liu, T.-C.; Lin, T.-Y. Proc. SPIE-Int. Soc. Opt. Eng. 1999, 3678 (Part 2 , Advances in Resist Technology and Processing XVI), 1388-1395.

(18) Kanda, H.; Kanna, S.; Inabe, H. Jpn. Kokai Tokkyo Koho 2005 JP 2005234015 A2 20050902 CAN 143:257061 AN 2005:960420.
(19) Hagiwara, M. Jpn. Kokai Tokkyo Koho 2005 JP 2005156816 A2 20050616 CAN 143:50712 AN 2005:522625.

(20) Momota, M.; Nakao, H. U. S. Pat. Appl. Publ., 2004, US 2004202954 A1 20041014 CAN 141:358073 AN 2004:857028.

(21) Takahashi, A.; Sato, K. Jpn. Kokai Tokkyo Koho 2005, JP 2005099275 A2 20050414 CAN 142:382188 AN 2005:323286.

(22) Takahashi, H. Eur. Pat. Appl. 2005, EP 1522891 A1 20050413 CAN 142:382184 AN 2005:315680.

(23) Kanda, H.; Mizutani, K. Jpn. Kokai Tokkyo Koho 2005, JP 2005010392 A2 20050113 CAN 142:123179 AN 2005:33944.

(24) Zumsteg, F. C.; Leffew, K. W.; Feiring, A. E.; Crawford, M. K.; Farnham, W. B.; Petrov, V. A.; Schadt, F. L., III; Tran, H. V. J. Photopolvm. Sci. Technol. 2005, 18, 467-469.

(25) Sanders, D. P.; Connor, E. F.; Grubbs, R. H.; Hung, R. J.; Osborn, B. P.; Chiba, T.; MacDonald, S. A.; Willson, C. G.; Conley, W. Macromolecules 2003, 36, 1542.

(26) Smart, B. E. In Chemistry of Organic Fluorine Compounds II. A Critical Review; Hudlicky, M., Pavlath, A. E., Eds.; ACS Monograph 187; American Chemical Society: Washington, DC, 1995; pp $777-$ 791.

(27) Tabushi, I.; Yamamura, K.; Yoshida, Z. J. Am. Chem. Soc. 1972, 94 , 787-792.

(28) Petrov, V. A.; Davidson, F.; Smart, B. E. J. Fluorine Chem. 2004, $125,1543-1552$.

(29) Babadzhanova, L. A.; Kirij, N. V.; Yagupolskii, Yu. I.; Tyrra, W.; Naumann, D. Tetrahedron 2005, 61, 1813.

(30) Prakash, G. K. S.; Mandal, M. J. Fluorine Chem. 2001, 112, 123.

(31) Qian, C. P.; Nakai, T. Tetrahedron Lett. 1988, 29, 4119.

(32) Golubev, A. S.; Galakhov, M. V.; Kolomiets, A. F.; Fokin, A. V. Izv. Akad. Nauk, Ser. Khim. 1992, 2763-2767.

(33) Petrov, V.; Marshall, W.; Krespan, C. G.; Cherstkov, V. F.; Avatisian, E. A. J. Fluorine Chem. 2004, 125, 99-105.

(34) Feiring, A. E.; Schadt, F. L., III; Petrov, V. A.; Smart, B. E.; Farnham, W. B. PCT Int. Appl. 2004 WO 2004014964 A2 20040219 CAN 140: 181995.

(35) Feiring, A. E.; Schadt, F. L.; III; Petrov, V. A.; Smart, B. E.; Farnham, W. B. PCT Int. Appl. 2004 WO 2004014964 A2 20040219 CAN 140: 181995.

(36) Adam, W.; Saha-Moller, C. R.; Weichold, O. J. Org. Chem., 2000, 65, 2897.

(37) Adolfson, H.; Coperet, C.; Chiang, J. P.; Yudin, A. K. J. Org. Chem. 2000, 65, 8651

(38) Brasen, W. R. US 29288651960 CAN 54:97308.

(39) Wiley, D. W.; Simmons, H. E. J. Org. Chem. 1964, 7, 1876.

(40) Weinmayr, V. J. Org. Chem. 1963, 28, 492-4.

(41) Connor, E. F.; Younkin, T. R.; Henderson, J. I.; Hwang, S.; Grubbs, R. H.; Roberts, W. P.; Litzau, J. J. J. Polvm. Sci.. Part A: Polvm. Chem. 2002, 40(16), 2842-2854.

(42) Crivello, J. V. J. Polvm. Sci., Part A, 1995, 33, 513-523.

MA060070B 